\title{
Invitro Impact of Diallyl Disulphide (Dads) on the Biochemical Components of the Cell Envelope of Staphylococcus Aureus Atcc 25293
}

\section{Farheen Fatima ${ }^{1}$ and Kashinath RT $^{2}$}

${ }^{1}$ Assistant professor, Department of MLT, Faculty of Applied Medical Sciences, University of Tabuk, Kingdom of Saudi Arabia

${ }^{2}$ Professor, Department of Biochemistry, SIMS \&RC, Shivamogga, Karnataka, India

*Corresponding author: Farheen Fatima, Assistant professor, Dept. of MLT, Faculty of Applied Medical Sciences, University of Tabuk, Tabuk, Kingdom of Saudi Arabia, Email: farheenkhizar@ yahoo.com

\section{Research Article}

Volume 3 Issue 1

Received Date: March 20, 2020

Published Date: May 29, 2020

DOI: $10.23880 /$ aabsc-16000149

\section{Abstract}

Diallyl Disulphide (DADS) is a phytochemical found in the plants of the genus Allium. It is the principal organosulphuric component of distilled garlic oil. Many medicinal benefits like antimicrobial, antiviral and insecticidal are attributed this compound. However the biochemical explanation for such an action remains unexplored. This current study strives to explore the explanation for antimicrobial activity of the compound using the most common skin inhabitant Gram positive bacteria, commonly causing nosocomial infections- Staphylococcus aureus.

The Minimum Inhibition Concentration (MIC), Minimum Bactericidal (MBC) Concentration of DADS, its effect on growth curve and time kill curve of $S$. aureus has been established. In the current study $S$. aureus was cultured in the broth containing 1/8 MIC of DADS. The staphylococcal cells were harvested; biochemical components were extracted and quantitated using appropriate biochemical analytic tests.

The biochemical components focused on were of those abundantly present and those that contribute to the materialization of the staphylococcal cell envelope total lipids, total lipid phosphorous and total carbohydrates.

The biochemical component extracts of $S$. aureus tested revealed significant reduction in the total lipids (70\%), total lipids phosphorous (50\%) and total carbohydrates (34\%). This reduction in the components may be attributed to the hypolipidemic and hypoglycemic properties of DADS and could further lead to changes in the anabolic processes.

Since the cell envelope of the bacterial cell is primarily made up of lipids, phospholipids and peptidoglycan (a carbohydrate polymer). The evident reductions in the studied components indicate reflective impact of DADS on the cell envelope of $S$. aureus. This study can be extrapolated in innovation of a new phytochemical-antibiotic against the life threatening multidrug resistant human pathogens.

Keywords: Diallyl Disulphide; Cell Envelope; Staphylococcus Aureus; Minimum Inhibition Concentration (MIC); Minimum Bactericidal (MBC) Concentration; Growth Curve; Time Kill Curve; Total Lipids; Total Lipids Phosphorous; Total Carbohydrates 


\section{Introduction}

The Staphylococcus aureus is gram positive cocci appearing in 'grape like clusters'. These are among the most common bacteria inhabiting the skin, cutaneous glands and mucous membranes of mammals [1]. The nose is a most common habitat for S.aureus [2]. A rate of S. aureus carriage is higher in those infected with HIV compared with health care workers and patients with range of chronic diseases [3]. The carriage rates are also higher in individuals with insulin dependent diabetes, in patients on continuous ambugalatory peritoneal dialysis and hemodialysis and in intravenous drug abusers when compared to healthy populations [4].

S.aureus is common and important pathogen causing community acquired, hospital acquired and toxin mediated diseases. The community acquired infections include toxin mediated infections affecting skin and soft tissue; infection of bones and joints, infection relating to other deep sites, and infection of the lung and the urinary tract. This conditions occur both in those with known risk factors, and in individuals who were previously fit and healthy. Ventilator-associated pneumonia, bacteremia associated with intravenous devices, and infection associated with other types of prosthetic materials such as cerebrospinal fluid shunts, prosthetic joints, and vascular grafts. The most common deep seated infections are endocarditis and bone and joint infections [5].

The dry cellular mass harvested from the cell culture invitro mainly consists of the constituents of the cell envelope of the bacteria and a very minute amount of the intracellular structures.

The cell envelope of the S.aureus typically consists of cell wall and cell membrane. The microcapsule although may be present, often in the fresh isolates from the clinical specimens [6].

The cell membrane is typical lipid-protein bilayer composed mainly of phospholipids and proteins the phospholipids and glycolipids are major components of the lipids in the cell membrane of the S.aureus [7-9].

50-60\% dry weight of S.aureus consists of carbohydrate polymer peptidoglycan and teichoic acid. The peptidoglycan is the carbohydrate polymer that plays important role in manufacturing the structural shape of the cell.

Herbs and herbal extracts have been used in medicine since ages. Many of the pharmaceutical preparations used by physicians even today have a long history of use as herbal remedies, including opium, aspirin, digitalis and quinine. The World Health Organization (WHO) survey states that $80 \%$ of the world's population presently uses herbal medicine for some aspect of primary health care [10].

It also states $25 \%$ of modern drugs used in the United States have been derived from plants [11]. Also 7000 medicine compounds in the modern pharmacopoeia are derived from plants [12]. The most significant are the garlic and its extracts, as well as garlic related phytochemicals. Garlic (Allium Sativum Linn) has a long history as a treatment for cold, cough and asthma, and is reported to strengthen immune system [13]. It has many medicinal effect such as lowering blood cholesterol level, anti-platelet aggregation, anti-inflammatory activity ${ }^{13}$ and inhibition of cholesterol synthesis [14-16]. It has also been known to have antibacterial, antifungal, anticancer and antiviral properties [17-21]. The main antimicrobial constituents of garlic have been identified as the oxygenated sulphur compound, Thio-2-propane 1- sulfinic acid S-alkyl ester, which is referred as allicin [22]. Hughes and Lawson showed that antimicrobial activity of garlic is completely abolished when the thiosulfinates are removed from the extracts [23].

Diallyl Disulfide (DADS) is an organosulphur compound found in plants of the genus Allium. Along with diallyltrisulphide and diallyltetrasulfide, it is one of the principle components of the distilled oil of garlic. Many properties including antimicrobial, insecticidal and larvicidal have been attributed to this compound of garlic oil [24].

Though garlic, its extracts and garlic oil have a significant antimicrobial activity as well as anti-staphylococcal functions, the exact garlic component showing these activities is not precisely explored. DADS, the principle organosulphur component of garlic oil which is responsible for many of the beneficial functions of garlic is thought to be responsible for garlic's antimicrobial actions. The mechanism or biochemical explanation fo0r such an action of either garlic extracts or its organosulphur compounds have not been established. Hence the current study explores the in-vitro impact of diallyldisulphide (DADS) on the biochemical components of the cell envelope of Staphylococcus aureus ATCC 25293 which may be explanation of one of the mechanism of action of DADS.

Earlier the Minimum Inhibitory concentration (MIC), Minimum bactericidal concentration (MBC) against nosocomial pathogens and effect DADS on growth curve and time kill curve has been published $[25,26]$. In the current study the in-vitro impact of diallyldisulphide (DADS) on the biochemical components of the cell envelope of Staphylococcus aureus ATCC 25293 are presented.

Since the major biochemical constituents of the cell envelope are lipids and carbohydrates this study states the 
changes in lipid and carbohydrates components of the cell mass of S.aureus induced by DADS with respect to the cell mass of controls(without DADS).

\section{Materials and Methods}

All the chemicals employed in this study were of analar grade (A.R) DADS was procured from SigmaAldrich chemicals Pvt. Ltd. USA. All media used were of dehydrated media purchased from Himedia Pvt.Ltd. India. Staphylococcus aureus ATCC strain 25293 was procured from St. John's Medical College, Bangalore.

The study was consisted of two study groups: Control group-consisting of strains grown in Mueller Hinton broth (MHB) without DADS, and test group- consisting of strains grown in MHB with sub-minimum inhibition concentration of DADS.

The data entry was carried out using Microsoft Office Excel worksheet and statistically analyzed. The $\mathrm{p}$ value was calculated from the student' $t$ ' test.

The experiments were conducted as per the norms of institutional ethical committee of Basaweshwara Medical College, Chitradurga, and Karnataka, India.

\section{Growth Harvest}

The MHB was prepared as per the manufacturer's directions and autoclaved and checked for sterility by incubating the media at $37^{\circ} \mathrm{C}$ for $18-24$ hours. The sterile broth was inoculated with standard inoculum of 0.5 McFarland turbidity. The broth was incubated for 48 hours and subculture was done from this culture onto a fresh nutrient agar in order to ensure purity of the growth. Further this MHB proceeded for harvesting the growth for biochemical parameter studies.

\section{Bacterial Growth Harvest}

The growth was subjected to centrifugation for 10 minute at $5000 \mathrm{rpm}$. The supernatant was discarded and the sediment was collected, weighed and used for extraction and estimation of total lipids, phospholipids and carbohydrates.

\section{Extraction of Carbohydrates}

The harvested cell mass was homogenized with 9 parts of phosphate buffer $(\mathrm{pH}=7.4)$ using Potter Elvejham tissue homogenizer for 10 minutes. The homogenate was centrifuged for 5 minutes at $5000 \mathrm{rpm}$. The supernatant was used for the estimation of total carbohydrates [27].

\section{Extraction of Cellular Lipids}

The harvested cell mass homogenized with 9 parts of chloroform-methanol mixture $(1: 1, \mathrm{~V} / \mathrm{V})$ using Potter Elvejham tissue homogenizer for 10 minutes. The homogenate was centrifuged for 5 minutes at $5000 \mathrm{rpm}$. The supernatant was used for the estimation of lipids and phospholipids [28].

\section{Estimation of Total Lipids}

Total lipids in the extract were estimated by Sulphovanillin reaction of Chabro and Charronat, as given by Choudary [29]. The total lipid content in growth extract was reported in milligrams and was calculated using the following equation and were reported in $\mathrm{mg} / \mathrm{g}$ growth.

Mg total lipid $/ g$ growth $=\frac{\text { Absorbance of Test }- \text { absorbance of Blank }}{\text { Absorbance of Standard }- \text { absorbance of Blank } 0.005} \times 1$

\section{Estimation of Total Phospholipids}

Phospholipids in the harvested cell mass homogenates were estimated by the modified method of Youngberg and Youngberg as described Nath RL [30]. The lipid phosphorous content in the growth extract was estimated using the following equation and reported in milligrams per gram growth.

Mg lipid phosphorous $/ \mathrm{g}$ growth $=\frac{\text { Absorbance of unknown }}{\text { Absorbance of standard } 0.033} \times 1$

\section{Estimation of Total Carbohydrates}

The total carbohydrate was estimation using Folin wu's Phenol-Sulphuric acid method. The total carbohydrate content in the growth was estimated using the following equation and reported in milligrams per gram growth.

Mg total carbohydrate $/ g$ growth $=\frac{\text { Absorbance of the test }}{\text { Absorbance of Standard }} \times$ Concentration of Standard

\section{Results and Discussion}

The DADS induced biochemical effects in S. aureus ATCC 252933 was studied by culturing the bacteria in MHB containing 1/8 X MIC of DADS (test) as well as in MHB without DADS (control).

The results of the experiments conducted to study the effect of DADS on the content of total cellular lipid, total cellular lipid phosphorous, total cellular carbohydrates of the S.aureus ATCC 25293 is given in table No. 1 and depicted in the following graph. 


\begin{tabular}{|c|c|c|c|c|c|c|}
\hline \multirow{2}{*}{ Set } & \multicolumn{2}{|c|}{ Total lipid cellular content } & \multicolumn{2}{c|}{ Total cellular lipid phosphorus } & \multicolumn{2}{c|}{ Total cellular carbohydrates } \\
\cline { 2 - 7 } & Control & Test & Control & Test & Control & Test \\
\hline Series 1 & 3.293 & 0.8 & 0.101 & 0.053 & 2.35 & 1.65 \\
\hline Series 2 & 2.667 & 0.9 & 0.098 & 0.040 & 2.35 & 1.49 \\
\hline Series 3 & 3.105 & 0.9 & 0.105 & 0.055 & 1.81 & 1.44 \\
\hline Series 4 & 3.227 & 1.0 & 0.112 & 0.047 & 2.4 & 1.44 \\
\hline Series 5 & 3.057 & 1.0 & 0.102 & 0.050 & 2.4 & 1.44 \\
\hline Average & 3.0698 & 0.92 & 0.104 & 0.049 & 2.262 & 1.49 \\
\hline p Value & \multicolumn{7}{|c|}{$<\mathbf{0 . 0 5}$} \\
\hline
\end{tabular}

Table 1: The results of the experiments conducted to study the effect of DADS on the content of total cellular lipid, total cellular lipid phosphorous, total cellular carbohydrates of the S.aureus ATCC 25293.

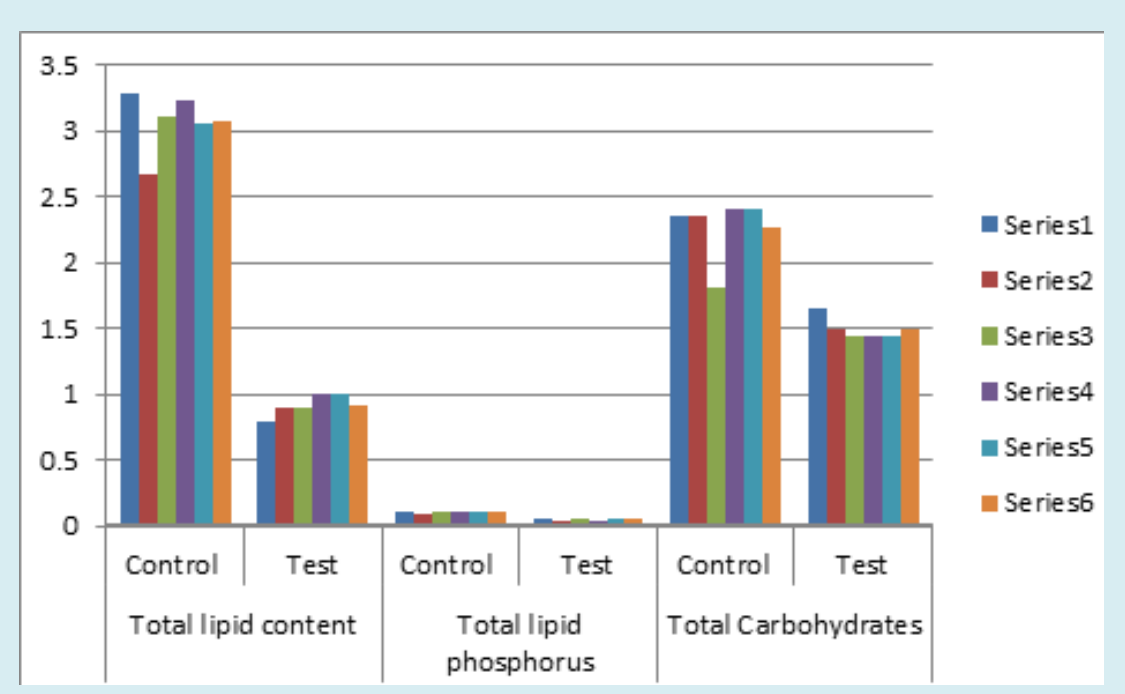

Graph 1: The effect of DADS on the content of total cellular lipid, total cellular lipid phosphorous, total cellular carbohydrates of the S. aureus ATCC 25293.

As evident from the table and the graph, in the tested bacterial cell mass, the total cellular carbohydrate content is reduced by $34 \%$; the total cellular lipid phosphorus content is approximately halved, whereas the total cellular lipid is significantly reduced by $70 \%$ in the test groups in comparison with the control groups.

Several research studies have consistently confirmed the beneficical effects of garlic (Allium sativum Linn) and its extracts [31,32]. Most of these effects are attributed to their organosulphur compounds. The principle organosulphur compound of garlic extract is DADS 33 and its most predominant beneficial effect is antimicrobial action [32].

The antimicrobial action of DADS in terms of its MIC and $\mathrm{MBC}$ has been reported as $1 \mathrm{mg} / \mathrm{L}$ and $2 \mathrm{mg} / \mathrm{L}$ respectively [25]. The effect of DADS on growth curve and time kill kinetics have also been explored and found to significant [26].
In the current study, invitro impact of DADS on the biochemical components of the cell envelope of S.aureus ATCC 25293 was explored to extrapolate the earlier studies and derive a probable explanation for such an action.

Many metabolic activities of the bacterial cell differ significantly from those of the human cell. Theoretically these differences can be exploited in the chemotherapy for infections. Generally an antimicrobial substance has one or more mode of action including: inhibition of cell wall synthesis, alterations in cell membrane, inhibition of nucleic acid synthesis and anti-metabolic activity.

Although few other studies established antistaphylococcal action of DADS studies to evaluate the explanation of such an action are meager. As stated in the results, the biochemical components of the bacterial cell mass; total lipids, total phospholipids and total carbohydrates 
are decreased significantly [32-34].

DADS, a known hypolipidemic compound decreases the lipid levels by decreasing the available NADPH levels. The Total cellular lipid content was decreased $(70 \%)$ in the test group in comparison with control groups indicate that a similar DADS induced NADPH mediated hypolipidemic action might have occurred [35].

The decrease in the total cellular phospholipid content of the test group (53\%) are in agreement with the reports of Yousuf et.al stating decrease in the phospholipid content in Candida sps [36]. This may be attributed to DADS induced decrease in the activity of enzyme glycerol phosphate dehydrogenase [35].

The decrease in total cellular carbohydrate (34\%) may be due to DADS induced (i) inactivation of the thiol enzyme $\mathrm{N}$-arylamine $\mathrm{N}$-acetyl transferase or (ii) hypolidemic activity. Peptidoglycan, which is the major form of carbohydrate in the bacterial cell, requires lipid II as the precursor and the enzyme $\mathrm{N}$-arylamine $\mathrm{N}$-acetyl transferase for its biosynthesis $[37,38]$.

Overall decrease in the biochemical components of the staphylococcal cell mass explored in the invitro current study indicates the garlic derived allyl compound DADS has great impact on its cell envelope, thereby resulting in its antistaphylococcal action.

\section{Conclusion}

Although the current study indicates significant impact of DADS on the cell envelop components of S.aureus further studies in this regard are essential to explain the exact mechanism for anti-staphylococcal action of DADS. The study may be extrapolated in discovery of new antimicrobial phytochemical that may be solely used for treatment or may be used as an additive to the antimicrobial compounds to treat multi drug resistant bacterial infections.

\section{Declaration}

The authors declare no conflict of interest. The authors alone are responsible for the content and writing of this manuscript.

\section{Acknowledgment}

We acknowledge the generous support for the conduct of this research by Basaweshwara Medical College and Research Center, SJM Vidyapeeta, Rajiv Ghandhi University of Health Sciences, Chitradurga, Karnataka, India.

\section{References}

1. Kloos WE, George CG (1991) Identification of Staphylococcus species and sub species with microscan Pos ID and Rapid Pos ID panel systems. J Clin Microbiol 29(4): 738-744.

2. Kinsman OS, McKenna R, Noble WC (1983) Association between histocompatibility antigens (HLA) and nasal carriage of Staphylococcus aureus. J Med Microbiol 16(2): 215-220.

3. Wilkinson BJ (1983) Staphylococcus capsules and slime. In: Easmon C.S.F and Adlam, C(Eds), Staphylococci and Staphylococcal infections, London: Academic Press 2: 481-523.

4. Kluytmans J, Belkum VA, Verbrug H (1997) Nasal Carriage of Staphylococcus aureus: Epidemiology, underlying mechanism and associated risks. Clin Microbiol Rev 10(3): 505-520.

5. Fowler V, Olsen MK, Corey GR, Woods CW, Cabell CH, et al. (2003) Clinical identifiers of complicated Staphylococcus aureus bacteremia. Arch Int Med163(17): 2066-2072.

6. Ing Marie $\mathrm{N}$, Lee JC, Bremell T, Ryde CN, Tarkowski A (1997) The Role of Staphylococcal Polysaccharide Microcapsule Expression in Septicemia and Septic Arthritis. Inf and Imm 65(10): 4216-4221.

7. Lange Microbiology, Section I. Fundamentals of Microbiology; Chapter 2, Cell Structure. The McGrawHill Companies. 2007: 9-51.

8. Nahaie MR, Goodfellow M, Minnikin DE, Hajek V (1984) Polar lipid and isoprenoid quinine composition in the classification of Staphylococcus. J Gen Microbiol 130(9): 2457-2437.

9. Shaw N (1975) bacterial glycolipids and glycosylloids. Adv Microbiol Physiol 12: 141-167.

10. http://www.who.int.mediacenter/factssheets/fs134/ en/.

11. http://en.wikipedia.org/wiki/herbalism.

12. http://www.ienica.net/reports/ienicafinalsummaryreport

13. Borek C (2001) Antioxidant health effects of aged garlic extract. J Nutr Sci 131(3): 1010-1015.

14. Yeh Y, Yeh S (1994) Garlic reduces plasma lipids by inhibiting hepatic cholesterol and triglycerol synthesis. Lipids 29(3): 189-193. 
15. Steiner M, Kham AH, Holbert D, Lin RI (1996) A double blind cross over study in moderately hypocholestermic men that compared the effect of aged garlic extractand placebo administration in blood lipids. A J Clin Nutr 64(6): 866-870.

16. Piscitelli SC, Burstein AH, Welden N, Gallicano KD, Felloon J (2002) The effect of garlic supplements on the pharmacokinetics of saquinavir. Clin Infect Dis 34(2): 234-238.

17. Cellini LE, Di Campli E, Masulli M, Di Bartolomeo S, Allocati N (1996) Inhibition of Helicobacter pylori by garlic extract (Allium sativum). FEMS Immunol Med Microbiol 13(4): 273-277.

18. Ekweney UN, Elegalan NN (2005) Antibacterial activity of ginger and garlic extracts on Escherichia coli and Salmonella typhi. J Mol Med Adv Sci 1(4): 411-416.

19. Yoshida SS, Kasuga N, Hayashi T (1987) Antifungal activity of garlc of ajoene derived from garlic. Appl Environ Microbiol 53(3): 615-617.

20. Pan XY, Lif Q, Yu RJ (1985) Comparision of cytotoxic effects of fresh garlic diallyltrisuphide, 5-flurouracil, mitomycn and cis-DDP on two lines of gastric cancer cells. Chin J Oncol 7(2): 103-105.

21. Block E (1985) Chemistry of garlic and onions. Sci Am J 252(3): 94-95.

22. Cavillito CJ, Bailey JH (1944) Allicin, the antibacterial principle of Allium sativum, isolation, physical properties and antibacterial action. J Am Chem Soc 65(11):19501951.

23. Hughes BJ, Lawson DL (1991) Antibacterial effects of Allium sativum L. (garlic), Allium Ampeloprasum (Elephant garlic), and Allium cepa (onion), garlic compounds and commercial garlic supplement products. Phytother Res 5(4): 154-158.

24. Amonkar SV, Banerji A (1971) Isolation and charecterisation of larvicidal principle og garlic. Sci 174(16): 1343-134.

25. Farheen F, Kashinath RT (2010) Antimicrobial activity of diallyldisulphide against human nosocomial pathogens. J Adv Res in Bio Sci 2.

26. Farheen F, Kashinath RT (2010) Effect of sub minimum inhibitory concentration of Di-allyl-di-sulphide (DADS) on the growth curve and time kill curve in staphylococcus aureus ATCC strain 25923. G J Med Res 10(3): 21-24. methods. J Ani Sci 81(12): 3226-3232.

28. Bligh EG, Dyer WJ (1959) A rapid method of total lipid extraction and purification. Can J Biochem Physiol 37(8): 911-917.

29. Chaudhari K (1989) biochemical tecniques. (Edn.), Jaypee Bros, New Delhi, pp: 112-114.

30. Nath RL. Practices of biochemistry in clinical medicine. Oxford \& IBH publishing Co. New Delhi/Bombay/ Calcutta; 81-83.

31. Mathew PT, Augusti KT (1973) Isolation of hypo and hyperglycemia agents from Allium cepa Linn. Ind J Exp Bio 11(6): 573-575.

32. Shyh Ming T, Mei Chin Y (2001) In-vitro antimicrobial activity of four Diallyl dulphides occurring naturally in garlic, Chinese leek oils. J Med Microbiol 50(7): 646-649.

33. Divya D, Vickram, Kashinath RT (2012) Protective effects of Diallyl disulphides in experimentally induced hepatoma in mice. G J Med Res 12(4): 59-63.

34. Cutler RR, Wilson P (2004) Antimicrobial activity of new, stable, aqeous extract of allicin against methicillin resistant Staphylococcus aureus. Br J Biomeed Sci 61(2): 71-74.

35. Kashinath RT Hypolipidemic effects of Diallyl Disulphides in rats fed high lipid diet and or ethanol. PhD thesis. St. John's Medical college, Bangalore University, Bangalore; 1993.

36. Yousef S, Ahmed A, Khan A, Manzoor N, Khan LA (2011) Effects of garlic derived allyl sulphides on morphogenesis and hydrolytic enzyme secretion in Candida albicans. Med Mycol 49(4): 444-448.

37. Guang wei C, Jig Guang C, Heng chen H, Juan geng L (1999) Effects of garlic compounds Diallyl Disulphide and Diallyl trisulphide on arylamine $\mathrm{N}$-acetyltransferase activity in Klebsiella pneuloniae. J Appl Toxicol 19(2): 75-81.

38. Eefjan B, Ben de K Lipid II as a target for antibiotics. Nat. drug Disc. 2012; 12(4): 59-63. 